\title{
Responsividade materna em famílias de mães solteiras e famílias nucleares no terceiro mês de vida da criança
}

\author{
Cesar Augusto Piccinini \\ Angela Helena Marin \\ Universidade Federal do Rio Grande do Sul \\ Patricia Alvarenga \\ Universidade Federal da Bahia \\ Rita de Cássia Sobreira Lopes \\ Universidade Federal do Rio Grande do Sul \\ Jonathan Richard Tudge \\ Universidade da Carolina do Norte-EUA
}

\begin{abstract}
Resumo
O presente estudo investigou a responsividade materna no terceiro mês de vida do bebê em famílias de mães solteiras e famílias nucleares. Participaram do estudo 21 díades mãe-bebê, das quais sete de mães solteiras e quatorze de mães casadas. Uma sessão de observação da interação livre entre mãe e bebê foi utilizada para a avaliação da responsividade materna. Foram examinadas 21 seqüências responsivas e três seqüências não-responsivas envolvendo o sorriso, as vocalizações e o choro do bebê. O Teste Mann-Whitney revelou diferenças significativas entre os dois grupos tanto nas seqüências responsivas, como nas não-responsivas, indicando que as mães solteiras foram menos responsivas do que as mães casadas, em especial, no que se refere à vocalização e ao choro do bebê. Esses resultados corroboram parte da literatura que indica que as mães solteiras podem sofrer maior estresse quando precisam suprir sozinhas as demandas do bebê, principalmente no seu primeiro ano de vida, o que pode ter implicações para a relação da díade.
\end{abstract}

Palavras-chave: responsividade materna; interação mãe-bebê; mães solteiras

\begin{abstract}
Maternal responsiveness in single-mothers and two-parent families at three months of child's life. The present study investigated the maternal responsiveness in the third month of infant's life in single mothers' families and nuclear families. Twenty one mother-infant dyads participated in the study seven of which were single mothers and fourteen were married mothers. A free interaction session between mother and infant was observed for evaluation of maternal responsiveness. Twenty-one responsive sequences and three nonresponsive sequences involving infant's smile, vocalizations and cry were examined. Mann-Whitney test revealed significant differences between the two groups in the responsive and non-responsive sequences, indicating that single mothers were less responsive than the married mothers, especially regarding infant's vocalization and cry. The results give support to part of the literature that indicates that single mothers can suffer larger stress when they need to supply alone the infant's demands, mainly during his/her first year of life, which can have implications for the dyadic relationship.
\end{abstract}

Keywords: maternal responsiveness; mother-infant interaction; single mothers

$\mathrm{O}$ estudos sobre o apego têm demonstrado de forma consistente que o primeiro ano de vida é um período crítico para o desenvolvimento afetivo, cognitivo e social da criança (Ainsworth, Blehar, Waters, \& Wall, 1978; Bowlby, 1969; Landry, Smith, Swank, Assel, \& Vellet, 2001). Nesse período, é importante que os pais respondam ao comportamento de seus filhos com afeto e sensibilidade, favorecendo a formação do apego (Bowlby, 1969) e contribuindo para o seu desenvolvimento social e emocional (Ziv \& Cassidy, 2002).

Os conceitos de responsividade (Wakschlag \& Hans, 1999), 
sensibilidade (De Wolff \& Ijzendoorn, 1997; Isabella, Belsky, \& Von Eye, 1989) ou responsividade sensível (van den Boom, 1994) têm sido utilizados para designar características maternas desejáveis e necessárias para o desenvolvimento de um apego seguro entre a criança e sua mãe. Crianças que experienciam cuidados caracterizados por sensibilidade e responsividade materna tendem a desenvolver um padrão de apego seguro, que se traduz em confiança na disponibilidade emocional e responsividade da mãe, e que promovem uma orientação positiva e confiante da criança em relação a ela, ao mundo e a si mesma. De modo contrário, crianças que recebem cuidados caracterizados por pouca sensibilidade e baixa responsividade materna tendem a desenvolver um apego inseguro, que reflete falta de confiança na disponibilidade emocional da mãe e implicará em uma atitude negativa e pouco confiante da criança em relação a ela, ao mundo e a si mesma (Belsky \& Pasco Fearon, 2002).

A responsividade materna foi definida por Isabella et al. (1989) e van den Boom (1994) como a atenção e percepção consistentes, interpretação acurada e resposta contingente e apropriada aos sinais da criança. Esta característica da mãe favoreceria a ocorrência de interações sincrônicas e mutuamente recompensadoras na díade. Para Wakschlag e Hans (1999), a responsividade pode ser distinguida de outros atributos parentais positivos, como o afeto e a estimulação, porque envolve ações parentais que são contingentes a sinais da criança e que são apropriadas em relação aos seus desejos e necessidades, incluindo sua necessidade de autonomia. De acordo com esses autores, a responsividade não é um construto único, mas um domínio que consiste em um complexo de construtos e variáveis relacionadas, como, por exemplo, sensibilidade a pistas sociais, empatia, capacidade de previsão, não-intrusividade, disponibilidade emocional e envolvimento positivo.

Dentre os múltiplos fatores que podem estar relacionados à maternidade e, em especial, à responsividade materna, a configuração familiar e o apoio social fornecido pelo pai têm se destacado. Constata-se, nas sociedades ocidentais, um número cada vez maior de famílias uniparentais, que têm, na maioria dos casos, a mãe como progenitor responsável. Tal fato pode ser explicado em função dos altos índices de divórcio e da opção de mulheres por terem um filho enquanto solteiras. Conforme dados recentes do senso realizado pelo Instituto Brasileiro de Geografia e Estatística - IBGE (www.ibge.gov.br), aproximadamente $25 \%$ dos lares brasileiros estão sob a responsabilidade de mulheres, sendo estas solteiras, separadas, divorciadas ou viúvas. Independente das razões, a mudança que deixa a família a cargo de um só progenitor constitui um significativo reordenamento do sistema familiar. Assim, convive-se hoje com diversas configurações familiares, entre elas as famílias de mães solteiras e as tradicionais famílias nucleares, que se constituem no foco do presente estudo.

A família nuclear, também chamada de conjugal, é caracterizada como sendo composta por uma mulher, seu filho e o pai da criança, com quem vive matrimonialmente (Floresheim, Tolan, \& Gorman-Smith, 1998; Wagner, 2002). As famílias de mães solteiras, por sua vez, são definidas como aquelas constituídas de uma mulher não casada, que desde o início da gestação assumiu a responsabilidade de ter um filho sem a presença do pai biológico ou de alguém que o substituísse.

Os estudos que relacionam a configuração familiar e o comportamento materno apresentam alguns achados contraditórios. Algumas investigações com famílias afroamericanas indicaram que a presença do pai na família nuclear, bem como a presença de uma avó ou outro adulto que residia com famílias de mães solteiras, estaria associada com mais comportamentos maternos positivos e com o favorecimento do desenvolvimento infantil (Tolson \& Wilson, 1990; Wilson, 1986). No entanto, o estudo de Chase-Lansdale, Brooks-Gunn e Zamsky (1994) não encontrou relação entre a presença da avó e o comportamento materno em famílias de mães solteiras.

Apesar desses achados, considera-se que configurações familiares que contam com a presença de outros adultos, além da mãe, favorecem a maternidade e o desenvolvimento infantil (Heck \& Parker, 2002), em parte pelo aumento do apoio social dado à mãe por esses membros. Nesse sentido, a presença do pai ou de outro adulto na família somente teria impacto positivo sobre o comportamento materno quando esta pessoa, de fato, fornecesse apoio à mãe. Por exemplo, o estudo de Burchinal, Follmer e Bryant (1996) indicou que o apoio social, mais do que a configuração familiar foi um importante preditor da aceitação e do envolvimento materno com crianças de 20 meses.

Nessa perspectiva, estudos têm apontado que o tipo e a fonte do apoio são fatores importantes na compreensão do comportamento materno. Um estudo realizado por Feiring, Fox, Jaskir e Lewis (1987) teve como um dos objetivos investigar a relação entre o apoio social dado a mães de bebês com três meses de vida e o comportamento materno. Os autores indicaram que o apoio provido pelo pai da criança, parentes e amigos influenciava positivamente o comportamento materno. O apoio dado pelo pai, em especial, foi apontado como importante para a mãe, fazendo com que ela sentisse que ele também se interessava pelo bebê, mesmo que a ajudasse trabalhando fora de casa para sustentar a família. Corroborando esses achados, Dessen e Braz (2000), que investigaram a rede de apoio no momento do nascimento dos filhos em famílias brasileiras, indicaram que o apoio recebido do marido/companheiro foi considerado pelas mães o mais importante, seguido do apoio das avós maternas.

Estudos clássicos com bebês também enfatizaram o papel do pai no desenvolvimento infantil. De acordo com Winnicott (1965/1971), o pai teria tanto uma importância direta sobre o desenvolvimento de seus filhos, fornecendo os alicerces para as relações triangulares, como indireta, através do apoio dado à mãe.

A reflexão acerca da função paterna, sua influência no desenvolvimento infantil e o quanto sua ausência afeta a relação da mãe com a criança, dando origem a padrões distintos nesta relação, tem ganhado destaque entre alguns autores, que enfatizam que o pai já exerce uma influência sobre o desenvolvimento desde antes do nascimento (Brazelton, 1988; Parke, 1996; Stern, 1997). A presença do pai e o reconhecimento de que o bebê também é fruto do desejo deste, auxiliaria a mãe a compartilhar a responsabilidade da criação e dos êxitos ou fracassos em relação à criança, o que tenderia a minimizar seus 
sentimentos de ansiedade e incapacidade frente a esse novo papel.

Estudos têm mostrado que, mesmo que o pai possa estar, inicialmente, menos envolvido com a criança, pela própria natureza do vínculo simbiótico da gravidez, a partir do nascimento ele passa a ser cada vez mais importante para o desenvolvimento infantil. Stern (1997) destacou que a figura paterna teria papel importante na construção do apego da mãe com seu bebê, compartilhando com Winnicott (1965/1971) as idéias de que se a mãe se sentir amada como mulher pelo pai da criança, ela tende a cumprir mais facilmente seu papel de mãe. Parke (1996) também apontou que a presença do pai favorece o envolvimento da mãe com seu bebê. Segundo ele, as mães tendem a estimular, falar e sorrir mais para seus bebês quando seus maridos estão presentes, o que pode indicar que a presença do pai é um dos fatores que aumentaria o interesse da mãe pelo seu filho. Tais estudos mostraram uma relação positiva entre a presença do pai e o maior cuidado da mãe com o bebê, o que contribuiria para um desenvolvimento infantil saudável.

A literatura revisada indica que, entre os diferentes aspectos ou dimensões da relação mãe-criança, a responsividade materna aparece como um importante preditor de certos aspectos do desenvolvimento infantil, que podem ser avaliados já nas primeiras interações da mãe com o bebê. Contudo, poucos estudos investigaram as relações entre a responsividade materna e a configuração familiar, em particular quando da ausência paterna. Assim sendo, e considerando que o estudo de famílias de mães solteiras e famílias nucleares permite avaliar as implicações da presença do pai para o comportamento da mãe frente ao bebê, o presente estudo investigou a responsividade materna no terceiro mês de vida do bebê nestas duas configurações familiares.

\section{Método}

\section{Participantes}

Participaram deste estudo 21 díades mãe-bebê, sendo sete de famílias de mães solteiras (mãe-filho/a) e quatorze de famílias nucleares (pai-mãe-filho/a). A amostra foi selecionada, dentre os participantes do Estudo longitudinal de Porto Alegre: da gravidez à escola - ELPA (Piccinini, Tudge, Lopes, \& Sperb, 1998). Este estudo iniciou acompanhando 81 gestantes que não apresentavam intercorrências clínicas e que estavam esperando seu primeiro filho. Os bebês, nascidos a termo, não apresentavam problemas de saúde. Os maridos ou companheiros, também foram convidados a participar do estudo caso residissem juntos em situação matrimonial. Os participantes representavam várias configurações familiares (nucleares, uniparentais ou re-casados), diferentes idades (adultos e adolescentes) e com escolaridade e níveis socioeconômicos variados. $\mathrm{O}$ estudo envolveu várias fases de coletas de dados desde a gestação até os sete anos das crianças (gestação, $3^{\circ}, 8^{\circ}, 12^{\circ}, 18^{\circ}, 24^{\circ}, 36^{\circ}$ meses e $6^{\circ}$ e $7^{\circ}$ ano de vida da criança). Ele teve por objetivo investigar tanto os aspectos subjetivos e comportamentais das interações iniciais pai-mãe-bebê, assim como o impacto de fatores iniciais do desenvolvimento nas interações familiares, no comportamento social de crianças pré-escolares e na transição para a escola de ensino fundamental. O convite inicial para participar do estudo ocorreu quando a gestante fazia o pré-natal em hospitais da rede pública da cidade de Porto Alegre $(51,2 \%)$, nas unidades sanitárias de saúde do mesmo município $(7,4 \%)$, por meio de anúncio em veículos de comunicação $(26,8 \%)$ e por indicação (14,6\%).

Para fins do presente estudo, foram incluídas todas as mães solteiras $(n=7)$ e, a fim de aumentar a estabilidade da amostra, foram incluídas quatorze mães casadas ${ }^{1}$ conforme os critérios sugeridos por Fletcher, Fletcher e Wagner (1996). As mães solteiras eram de diferentes níveis socioeconômicos e foram emparelhadas com as mães casadas de acordo com o sexo da criança, a idade e a escolaridade da mãe e o nível socioeconômico da família. Todos os bebês eram saudáveis e nascidos a termo. As características sócio-demográficas da amostra encontram-se na Tabela 1 .

\begin{tabular}{|c|c|c|c|c|c|}
\hline Identificação & Idade & Escolaridade & Ocupação & Sexo da criança & NSE* \\
\hline \multicolumn{6}{|l|}{ Mães solteiras } \\
\hline 01 & 20 & $1^{\circ} \mathrm{G}$. incomp. & acompanhante & feminino & 1 \\
\hline 02 & 19 & $2^{\circ}$ G. incomp. & faz tricô & feminino & 1 \\
\hline 03 & 19 & $2^{2}$ G. comp. & cartoneira de bingo & masculino & 1 \\
\hline 04 & 20 & $2^{\underline{0}}$ G. comp. & dona-de-casa & masculino & 1 \\
\hline 05 & 22 & $2^{\circ}$ G. comp. & desempregada & feminino & 2 \\
\hline 06 & 25 & $2^{\circ}$ G. comp. & cabeleireira & masculino & 1 \\
\hline 07 & 28 & $3^{\circ} \mathrm{G}$. incomp. & agente de turismo & masculino & 3 \\
\hline \multicolumn{6}{|l|}{ Mães casadas } \\
\hline 08 & 23 & $1^{\circ}$ G. incomp & doceira & masculino & 1 \\
\hline 09 & 26 & $1^{\circ}$ G. incomp. & dona-de-casa & masculino & 1 \\
\hline 10 & 18 & $2^{\circ}$ G. incomp. & dona-de-casa & masculino & 1 \\
\hline 11 & 18 & $2^{\circ}$ G. incomp. & dona-de-casa & masculino & 1 \\
\hline 12 & 19 & $2^{2} \mathrm{G}$. comp. & dona-de-casa & masculino & 1 \\
\hline 13 & 19 & $2^{\underline{0}}$ G. comp. & dona-de-casa & feminino & 1 \\
\hline 14 & 20 & $2^{\underline{0}}$ G. comp. & dona-de-casa & masculino & 1 \\
\hline 15 & 20 & $2^{\underline{0}}$ G. comp. & auxiliar administrativa & masculino & 1 \\
\hline 16 & 20 & $2^{\underline{ }}$ G. comp. & telefonista & feminino & 2 \\
\hline 17 & 21 & $2^{\underline{o}}$ G. comp. & estagiária & feminino & 2 \\
\hline 18 & 22 & $2^{\underline{0}}$ G. comp. & vendedora & feminino & 2 \\
\hline 19 & 29 & $2^{\circ}$ G. comp. & técnica em enfermagem & feminino & 2 \\
\hline 20 & 26 & $3^{\circ} \mathrm{G}$. incomp. & auxiliar de escritório & feminino & 3 \\
\hline 21 & 27 & $3^{\circ} \mathrm{G}$. incomp. & técnica em enfermagem & masculino & 2 \\
\hline
\end{tabular}

\section{Delineamento, procedimento e instrumentos}

Foi utilizado um delineamento de grupos contrastantes (Nachmias \& Nachmias, 1996) visando comparar a responsividade materna entre o grupo de mães solteiras e o de mães casadas.

No terceiro trimestre de gestação, as gestantes preencheram a Ficha de Contato Inicial (Grupo de Interação Social, Desenvolvimento e Psicopatologia/GIDEP, 1998a), informando alguns dados sobre o casal. As famílias que preencheram os critérios do estudo (estar esperando o primeiro filho, estar no terceiro trimestre de gestação e não apresentar complicações físicas durante a gravidez), foram contatadas posteriormente por telefone, para agendar uma visita domiciliar. Durante esta visita, foram preenchidos o Termo de Consentimento Livre e Esclarecido (GIDEP, 1998b) e a Entrevista de Dados Demográficos (GIDEP, 1998c), entre outros instrumentos. 
Quando os bebês completavam três meses de vida, as famílias eram novamente contatadas por telefone e era marcada uma nova visita domiciliar. Nesta ocasião, era realizada a Observação da Interação Familiar - 3ํㅡês (GIDEP, 1999), para a avaliação da responsividade materna, sendo filmada em videotape.

A sessão de observação era composta por uma seqüência de quatro episódios de interação livre entre os membros da família: pai-mãe-bebê, pai-bebê, mãe-bebê, e novamente paimãe-bebê. As famílias de mães solteiras foram observadas apenas na seqüência de interação livre mãe-bebê. Cada episódio da seqüência teve duração de oito minutos. Foi solicitado às famílias que interagissem livremente com seus bebês, como faziam normalmente quando estavam juntos. No caso das famílias nucleares, o pai foi solicitado a se retirar do local durante a filmagem da interação mãe-bebê para evitar possíveis interferências, sendo o mesmo procedimento utilizado com a mãe durante o episódio pai-bebê. A sessão de observação foi filmada na residência das famílias por pesquisadores do Núcleo de Infância e Família, do Grupo de Interação Social, Desenvolvimento e Psicopatologia (GIDEP/UFRGS), que durante a observação evitaram qualquer tipo de interação verbal ou comportamental com os participantes. Para fins do presente estudo, foi considerada apenas a interação livre da mãe com o seu bebê.

A análise da responsividade materna foi realizada com base nas propostas de vários autores (van den Boom,1994; Isabella, Belsky, \& von Eye,1989; Wendland-Carro, Piccinini, \& Millar, 1999) e adaptada para análise do terceiro mês de vida do bebê (Alvarenga, 2004). Foram considerados dois aspectos do comportamento materno em relação ao comportamento da criança: adequação e contingência. $O$ critério de contingência das respostas parentais foi avaliado com base no tempo - respostas parentais que ocorrem até doze segundos após o comportamento do bebê, conforme sugerido por van den Boom (1994). A adequação das respostas parentais foi avaliada com base no tipo de resposta apresentado pela mãe. Foram consideradas como respostas adequadas aos comportamentos do bebê, comportamentos maternos facilitadores da interação, como falar, sorrir, pegar no colo, embalar e estimular o bebê. A seleção destas categorias de comportamentos foi feita com base em alguns estudos sobre responsividade materna (van den Boom,1994; Isabella et al., 1989; Wendland-Carro et al., 1999).

Inicialmente, seis minutos do episódio de interação mãebebê (três minutos iniciais e três minutos finais) foram divididos em intervalos de 12 segundos. Nos primeiros 6 segundos eram registrados os comportamentos do bebê em três categorias distintas: sorri (o bebê visivelmente sorri); vocaliza (o bebê balbucia ou mexe a boca, fazendo tentativas de vocalização ou imitação da vocalização materna) e chora/choraminga (o bebê encontra-se visivelmente desconfortável, inquieto ou chora). As respostas maternas a esses comportamentos foram registradas no mesmo intervalo e no intervalo seguinte em sete categorias distintas: interpreta/fala pelo bebê (a mãe vocaliza colocando-se empaticamente no lugar do bebê, interpretando seu estado ou sinais); fala para o bebê (a mãe vocaliza falando com o bebê, cantando para ele ou emitindo sons); sorri para o bebê (a mãe sorri dirigindo seu olhar para o bebê - ambos estão no mesmo plano visual); pega no colo/embala/aconchega (a mãe pega o bebê no colo ou balança o bebê em seus braços ou pernas), acaricia/beija (a mãe beija, ou passa os dedos, a mão ou seu rosto no corpo ou rosto do bebê, afagando-o); toca/estimula fisicamente ou com objeto (a mãe toca o bebê com partes de seu corpo para estimulá-lo ou faz gestos com o auxílio de objetos/brinquedos para chamar sua atenção) e oferece bico/seio/mamadeira (a mãe dá a mamadeira, o bico ou o seio para o bebê).

Foram registrados todos os comportamentos da mãe e do bebê, entendendo-se que os comportamentos registrados não eram mutuamente excludentes. A seleção dos intervalos de análise foi realizada desconsiderando alguns momentos em que, por limitações técnicas da filmagem, tornou-se difícil observar ambos os membros da díade com clareza. Em uma segunda etapa da análise três categorias de comportamentos do bebê (sorri, vocaliza e chora/choraminga) e as sete categorias de comportamentos da mãe (interpreta/fala pelo bebê, fala para o bebê, sorri para o bebê, pega no colo/embala/aconchega, acaricia/beija, toca/estimula fisicamente ou com objeto e oferece bico/seio/mamadeira), foram combinadas formando seqüências responsivas e não-responsivas, considerando-se os critérios de contingência e adequação da resposta materna. As categorias sorri, vocaliza e chora/choraminga foram selecionadas dentre as cinco categorias de comportamentos do bebê para formarem as seqüências responsivas e não-responsivas, por envolverem comportamentos do bebê aos quais se espera que a mãe responda sensível e prontamente. O critério de contingência das respostas maternas foi avaliado com base no tempo (respostas maternas que ocorreram até doze segundos após o comportamento do bebê). A adequação das respostas maternas foi avaliada com base no tipo de resposta apresentado pela mãe. Foram consideradas como respostas adequadas aos comportamentos do bebê, comportamentos maternos facilitadores da interação, ou seja, todos os comportamentos maternos expressos nas sete categorias analisadas. Desta forma, derivaram-se 21 seqüências responsivas (bebê-mãe): sorri - interpreta/fala pelo bebê; sorri - fala para o bebê; sorri - sorri para o bebê; sorri - pega no colo/embala/aconchega; sorri - acaricia o bebê; sorri - tocal estimula fisicamente ou com objeto; sorri - oferece bico/seio/ mamadeira; vocaliza - interpretalfala pelo bebê; vocaliza - fala para o bebê; vocaliza - sorri para o bebê; vocaliza pega no colo/embala/aconchega; vocaliza - acaricia o bebê; vocaliza - toca/estimula fisicamente ou com objeto; vocaliza oferece bico/seio/mamadeira; chora/choraminga - interpretal fala pelo bebê; chora/choraminga - fala para o bebê; choral choraminga - sorri para o bebê; chora/choraminga - pega no colo/embala/aconchega; chora/choraminga - acaricia o bebê; chora/choraminga - tocalestimula fisicamente ou com objeto; chora/choraminga - oferece bico/seio/mamadeira; e três seqüências não-responsivas: sorri - não responde; vocaliza - não responde; chora-choraminga - não responde. Para cada uma das seqüências responsivas foi calculado o percentual de responsividade materna dividindo-se o número de ocorrências naquela seqüência pelo número de comportamentos do bebê em questão. Por exemplo, para a seqüência sorri - interpreta/ fala pelo bebê, calculou-se o percentual de sorrisos do bebê ao qual a mãe respondeu interpretando ou falando pelo bebê, 
dividindo-se a freqüência nesta categoria (sorri - interpreta/ fala pelo bebê), pela freqüência na categoria de comportamento infantil sorri. Este procedimento foi adotado para controlar o efeito do número de comportamentos apresentados pelo bebê durante os seis minutos analisados sobre a responsividade materna. Desta forma, evitou-se que mães de bebês mais ativos, isto é, que se comportaram com maior freqüência durante o período observado, fossem consideradas mais responsivas por esta razão. $\mathrm{O}$ mesmo procedimento foi adotado para se obter os percentuais nas seqüências não-responsivas. Na última etapa da análise descritiva da responsividade materna, foram calculadas as médias dos percentuais das seis categorias de seqüências responsivas envolvendo o sorriso do bebê, das sete categorias de seqüências responsivas envolvendo as vocalizações do bebê e das sete categorias de seqüências responsivas envolvendo o choro do bebê, obtendo-se assim, os percentuais médios de responsividade materna ao sorriso, às vocalizações e ao choro do bebê, respectivamente. A média desses três percentuais foi calculada para obter-se o percentual médio de seqüências responsivas, que foi utilizado neste estudo como o indicador geral da responsividade materna. De modo semelhante, foi calculado o percentual médio de seqüências não-responsivas, a partir dos valores das três seqüências não-responsivas: bebê sorri - mãe não responde; bebê vocaliza - mãe não responde e bebê choral choraming - mãe não responde. Este valor foi utilizado como indicador geral da não-responsividade materna.

A codificação dos vídeos foi realizada por dois codificadores independentes. A fidedignidade entre os dois codificadores foi estabelecida em $20 \%$ dos vídeos de interação mãe-bebê escolhidos aleatoriamente do banco de dados do ELPA. O coeficiente Kappa foi calculado separadamente para cada uma das categorias. Para as sete categorias de comportamentos maternos, o valor do coeficiente Kappa variou de $K=0,70$ a $K$ $=0,93(M=0,82)$. Para as cinco categorias de comportamentos infantis, o coeficiente Kappa variou de $K=0,71$ a $K=0,91$ ( $M$ $=0,81)$. O índice geral do coeficiente Kappa foi $K=0,82$.

\section{Resultados}

Com os dados da codificação descrita acima foi utilizado o Teste Mann-Whitney, para investigar as diferenças na responsividade materna entre o grupo de mães solteiras e o de mães casadas. A Tabela 2 apresenta o percentual médio, o desvio padrão e o nível de significância das seqüências responsivas e não-responsivas para os dois grupos.

Como pode ser visto, as principais diferenças significativas nas seqüências responsivas entre os dois grupos referiram-se às seqüências que envolviam o choro do bebê. Comparadas ao grupo de mães solteiras, as mães casadas falaram $(p<0,04)$ e ofereceram o bico, o seio ou a mamadeira $(p<0,03)$ com maior freqüência quando os seus bebês choravam ou choramingavam. Diferenças significativas também apareceram quando se examinou o total de seqüências responsivas envolvendo o choro, em que as mães casadas também apresentaram maior freqüência média do que as mães solteiras $(p<0,03)$.

Tabela 2

Incidência média, desvio padrão e nível de significância (Teste Mann-Whitney) dos percentuais das seqüências responsivas e nãoresponsivas maternas na interação diádica para o grupo de famílias de mães solteiras e de famílias nucleares

\begin{tabular}{|c|c|c|c|c|}
\hline Seqüências & Criança-Mãe & Mães solteiras $(n=7)$ & Mães casadas $(n=14)$ & $p$ \\
\hline \multirow{8}{*}{ Sorri } & Interpreta & $0,14(0,24)$ & $0,15(0,36)$ & 0,80 \\
\hline & Fala para o bebê & $0,25(0,43)$ & $0,24(0,42)$ & 1,00 \\
\hline & Sorri para o bebê & $0,21(0,39)$ & $0,13(0,34)$ & 0,48 \\
\hline & Pega no colo/embala/aconchega & $0,00(0,00)$ & $0,12(0,31)$ & 0,31 \\
\hline & Acaricia/beija & $0,00(0,00)$ & $0,01(0,03)$ & 0,48 \\
\hline & Toca/estimula fisicamente ou c/objeto & $0,28(0,49)$ & $0,31(0,46)$ & 0,89 \\
\hline & Oferece bico/seio/mamadeira & $0,00(0,00)$ & $0,00(0,00)$ & 1,00 \\
\hline & Total de seqüências responsivas/ sorriso & $0,13(0,15)$ & $0,14(0,18)$ & 0,87 \\
\hline \multirow[t]{8}{*}{ Vocaliza } & Interpreta/fala pelo bebê & $0,08(0,14)$ & $0,09(0,15)$ & 1,00 \\
\hline & Fala para o bebê & $0,37(0,45)$ & $0,46(0,44)$ & 0,81 \\
\hline & Sorri para o bebê & $0,08(0,14)$ & $0,02(0,09)$ & 0,24 \\
\hline & Pega colo/embala/aconchega & $0,03(0,09)$ & $0,18(0,27)$ & 0,15 \\
\hline & Acaricia/beija o bebê & $0,03(0,07)$ & $0,04(0,09)$ & 0,70 \\
\hline & Toca/estimula fisicamente ou c/ objeto & $0,13(0,24)$ & $0,37(0,39)$ & 0,16 \\
\hline & Oferece bico/seio/mamadeira & $0,00(0,00)$ & $0,03(0,01)$ & 0,50 \\
\hline & Total de seqüências responsivas/vocalizações & $0,10(0,05)$ & $0,17(0,16)$ & 0,45 \\
\hline \multirow[t]{9}{*}{ Chora/choraminga } & Interpreta/fala pelo bebê & $0,03(0,07)$ & $0,17(0,27)$ & 0,22 \\
\hline & Fala para o bebê & $0,16(0,27)$ & $0,58(0,46)$ & 0,04 \\
\hline & Sorri para o bebê & $0,00(0,00)$ & $0,02(0,06)$ & 0,31 \\
\hline & Pega colo/embala/aconchega & $0,08(0,13)$ & $0,36(0,39)$ & 0,11 \\
\hline & Acaricia/beija o bebê & $0,01(0,04)$ & $0,02(0,04)$ & 0,74 \\
\hline & Toca/estimula fisicamente ou c/ objeto & $0,16(0,37)$ & $0,34(0,36)$ & 0,17 \\
\hline & Oferece bico/seio/mamadeira & $0,00(0,00)$ & $0,23(0,31)$ & 0,03 \\
\hline & Total de seqüências responsivas/choro & $0,06(0,08)$ & $0,25(0,17)$ & 0,03 \\
\hline & Percentual médio de seqüências responsivas & $0,09(0,06)$ & $0,17(0,11)$ & 0,08 \\
\hline Sorri & Não responde & $0,14(0,24)$ & $0,04(0,13)$ & 0,20 \\
\hline Vocaliza & Não responde & $0,14(0,15)$ & $0,01(0,03)$ & 0,02 \\
\hline \multirow[t]{2}{*}{ Chora/choraminga } & Não responde & $0,11(0,19)$ & $0,00(0,00)$ & 0,01 \\
\hline & Percentual médio de seqüências não-responsivas & $0,13(0,10)$ & $0,003(0,009)$ & 0,001 \\
\hline
\end{tabular}


Quanto às seqüências não-responsivas, destacaram-se algumas diferenças significativas nas seqüências vocaliza - não responde $(p<0,02)$ e chora/choraminga - não responde $(p<$ $0,01)$, que apresentaram uma freqüência maior no grupo de famílias de mães solteiras do que no grupo de famílias nucleares. Ao se considerar o percentual médio do total de seqüências não-responsivas, a mesma tendência apareceu, indicando que as mães solteiras foram, de modo geral, menos responsivas $(p<0,001)$. Esses dados indicaram diferenças expressivas entre os dois grupos tanto nas seqüências responsivas envolvendo o choro, como nas não-responsivas envolvendo o choro e as vocalizações, apontando que as mães solteiras foram menos responsivas nestas categorias do que as mães casadas. Uma segunda análise utilizando o Teste Mann-Whitney foi realizada para se investigar eventuais diferenças nas categorias de comportamentos maternos e infantis para o grupo de mães solteiras e de mães casadas. Esta análise foi realizada com o objetivo de verificar diferenças entre os grupos tanto no envolvimento materno, quanto no envolvimento do bebê durante a interação. As Tabelas 3 e 4 apresentam os resultados das análises para os comportamentos maternos e infantis, respectivamente.
Como pode ser visto na Tabela 3, não houve diferenças significativas entre os comportamentos maternos do grupo de mães solteiras e do grupo de mães casadas. Entre as categorias examinadas, apenas as categorias acaricia/beija $(p<0,09) \mathrm{e}$ toca/estimula fisicamente ou com objeto $(p<0,09)$ apresentaram uma diferença marginal não-significativa, indicando que as mães casadas apresentaram uma freqüência maior de comportamentos nessas categorias do que as mães solteiras. Examinando o total de comportamentos maternos, verificou-se que as mães casadas apresentaram uma freqüência significativamente maior de comportamentos que as mães solteiras $(p<0,02)$. Com relação aos comportamentos infantis, apresentados na Tabela 4 , não apareceu nenhum padrão claro de comportamento do bebê associado aos dois grupos de famílias.

Juntos, os dados das duas tabelas revelam, de modo geral, poucas diferenças, sugerindo que tanto as mães, quanto os bebês dos dois grupos envolveram-se na interação de modo semelhante nas categorias examinadas. No entanto, o total de comportamentos maternos analisados indicou um maior envolvimento das mães casadas com seus bebês durante a interação.

Tabela 3

Incidência média, desvio padrão e nivel de significância (Teste Mann-Whitney) das categorias de comportamentos maternos na interação diádica para o grupo de famílias de mães solteiras e famílias nucleares.

\begin{tabular}{lccc}
\hline \multicolumn{1}{c}{ Comportamentos maternos } & $\begin{array}{c}\text { Mães solteiras } \\
(n=7)\end{array}$ & $\begin{array}{c}\text { Mães casadas } \\
(n=14)\end{array}$ & $p$ \\
\hline Interpreta fala do bebê & $3,86(2,97)$ & $6,43(4,89)$ & 0,38 \\
Fala para o bebê & $14,86(8,82)$ & $20,43(9,14)$ & 0,14 \\
Sorri para o bebê & $0,43(0,53)$ & $1,93(2,49)$ & 0,20 \\
Pega no colo/embala & $3,14(4,26)$ & $8,86(9,01)$ & 0,15 \\
Acaricia/beija & $2,00(2,52)$ & $5,21(5,29)$ & 0,09 \\
Toca/estimula fisicamente ou c/ objeto & $8,14(9,35)$ & $13,64(7,49)$ & 0,09 \\
Oferece bico/seio/mamadeira & $1,14(1,07)$ & $1,69(2,09)$ & 0,83 \\
\hline Total & $68,00(24,83)$ & $94,07(22,91)$ & 0,02 \\
\hline
\end{tabular}

Tabela 4

Incidência média, desvio padrão e nivel de significância (Teste Mann-Whitney) das categorias de comportamentos infantis na interação diádica no grupo de famílias de mães solteiras e famílias nucleares.

\begin{tabular}{lccc}
\hline \multicolumn{1}{c}{ Comportamentos infantis } & $\begin{array}{c}\text { Mães solteiras } \\
(n=7)\end{array}$ & $\begin{array}{c}\text { Mães casadas } \\
(n=14)\end{array}$ & $p$ \\
\hline Sorri & $1,14(1,46)$ & $1,43(2,84)$ & 0,57 \\
Vocaliza & $3,14(1,95)$ & $3,71(6,11)$ & 0,59 \\
Chora/choraminga & $2,43(3,64)$ & $4,71(5,44)$ & 0,34 \\
\hline Total & $6,71(4,31)$ & $9,86(10,24)$ & 0,68 \\
\hline
\end{tabular}

\section{Discussão}

O presente estudo investigou a responsividade materna no terceiro mês de vida do bebê em famílias de mães solteiras e famílias nucleares. Considerando todos os níveis de análise realizados, foram verificadas diferenças expressivas entre os dois grupos tanto nas seqüências responsivas, em particular com relação ao choro, como nas não-responsivas, quanto ao choro e as vocalizações, apontando que as mães solteiras foram menos responsivas do que as mães casadas. Além disso, examinandose os comportamentos maternos e infantis durante a interação, embora os resultados tenham mostrado semelhanças entre as mães e os bebês dos dois grupos nas diversas categorias examinadas, o total de comportamentos maternos revelou um maior envolvimento das mães casadas com seus bebês. Por outro lado, não apareceram diferenças claras nos comportamentos dos 
bebês nos dois grupos investigados.

Esses achados apóiam parte da literatura que examinou o impacto da ausência do pai no comportamento materno. Estudos têm destacado a importância da presença do pai sobre o comportamento da mãe, sobretudo através do apoio oferecido por ele (Brazelton, 1988; Parke, 1996; Stern, 1997). Além disso, o pai também favorece a visualização do bebê como um ser separado da mãe e como fruto do seu desejo, compartilhando, assim, a responsabilidade da criação dos filhos, o que tende a minimizar os sentimentos de ansiedade e incapacidade da mãe frente ao seu papel (Brazelton, 1988).

No entanto, é importante mencionar que nesse estudo, as principais diferenças encontradas na responsividade das mães solteiras e casadas referiram-se às seqüências que envolviam o choro do bebê. As mães casadas mostraram-se mais responsivas, especialmente, em relação aos sinais de desconforto ou aflição dos seus bebês. É possível que esses achados estejam indicando que o apoio paterno e a relação entre a mãe e o pai da criança tenham um impacto mais proeminente sobre a capacidade ou disponibilidade da mãe para responder de forma sensível e contingente a esse tipo de comportamento da criança que, em geral, tende a despertar maior ansiedade e desconforto na mãe. De qualquer modo, estudos revisados por Parke (1996) mostraram que a presença do pai tornava a mãe mais envolvida com seu bebê, fazendo com que ela estimulasse, falasse e sorrisse mais. De certa forma, achados semelhantes foram obtidos no presente estudo, pois as mães casadas, quando comparadas com as solteiras, apresentaram maior freqüência total de comportamentos durante a interação com seus bebês.

Cabe assinalar que estas diferenças se referem ao terceiro mês de vida dos bebês, período em que as mães estão ainda se adaptando à maternidade. Neste contexto, o apoio social, inclusive o do pai, tende a ter um papel mais relevante para a maternidade e interação mãe-bebê, do que em momentos subseqüentes do desenvolvimento da criança, quando diferenças devido a configurações familiares podem não ser mais tão relevantes. É sabido que as mães solteiras tendem a sofrer grande estresse quando precisam suprir sozinhas as demandas de tempo e energia requisitadas pela criança (Heck \& Parker, 2002), o que talvez seja mais evidente no primeiro ano de interação, podendo resultar em relações menos positivas com seu bebê. Acredita-se que, com o passar dos meses, outros agentes socializadores (como, por exemplo, parentes, creche) passem a atuar, facilitando o processo da maternidade. Isso pode ter um importante papel, especialmente, entre as mães solteiras, que tendem a, gradativamente, se adaptar à maternidade lançando mão de recursos para atender adequadamente as demandas inerentes à função materna. Conforme afirmam Hertz e Ferguson (1998), com o passar dos anos, as mães solteiras tendem a buscar maneiras de equilibrar o trabalho e a família a fim de disporem de mais tempo para se dedicar a esta última e procuram desenvolver soluções individuais para ativar algumas redes de apoio social.

É necessário considerar, ainda, as limitações do presente estudo, que envolveu uma amostra pequena e apenas um tipo de avaliação da responsividade materna. Além disso, não foram controladas outras variáveis relevantes, como a participação e o envolvimento do pai com o bebê nas famílias de mães solteiras e a presença de outros adultos cuidadores residindo com as famílias. Sugere-se que novas investigações sejam conduzidas, examinando tais questões em amostras maiores e com diferentes abordagens metodológicas, utilizando, por exemplo, entrevistas ou situações de observação estruturadas. Também poderiam ser consideradas, além da presença do pai, a quantidade e os diferentes tipos de apoio social disponíveis à mãe (Burchinal et al., 1996; Feiring et al., 1987).

Apesar destas limitações, os achados do presente estudo sugerem que a presença do pai em famílias com crianças pequenas parece favorecer comportamentos maternos facilitadores da interação mãe-bebê, como a responsividade, e, conseqüentemente, o desenvolvimento infantil. Como enfatiza Bowlby (1989), ser mãe de uma criança pequena não é um papel fácil de ser exercido, tendo em vista o tempo e a atenção que os filhos demandam. Para o autor, a tarefa de cuidar de uma criança não é para uma só pessoa e requer apoio, seja do pai ou de outras pessoas, para que ela se torne mais leve e prazerosa. Neste sentido, é importante que os profissionais de saúde estejam atentos para as eventuais demandas das mães, especialmente das solteiras que, muitas vezes, sem apoio emocional e social adequado, precisam dar conta dos cuidados exaustivos que requer uma criança pequena, em particular no seu primeiro ano de vida. $\mathrm{O}$ olhar atencioso dos profissionais a estas mães permitirá um atendimento preventivo e de apoio para que elas possam se adequar e responder da melhor forma possível as exigências da maternidade.

\section{Referências}

Ainsworth, M., Blehar, M., Waters, E., \& Wall, S. (1978). Patterns of attachment: a psychological study of the strange situation. Hillsdale: Erlbaum.

Alvarenga, P. (2004). Problemas de externalização e competência social na infância: o impacto do temperamento infantil, da responsividade e das práticas educativas maternas. Tese de doutorado não-publicada, Universidade Federal do Rio Grande do Sul, Porto Alegre.

Belsky, J., \& Pasco Fearon, R. M. (2002). Early attachment security, subsequent maternal sensitivity, and later child development: does continuity in development depend upon continuity of caregiving? Attachment \& Human Development, 4(3), 361-387.

Bowlby, J. (1969). Attachment and loss: Vol. 1. Attachment. Nova York: Basic Books.

Bowlby, J. (1989). O cuidado com as crianças (S. M. de Barros, Trad.). In Uma base segura: implicações clínicas da teoria do apego (pp. 17-32). Porto Alegre: Artes Médicas.

Brazelton, T. B. (1988). Gravidez: o nascimento do apego (D. Batista, Trad.). In O desenvolvimento do apego: uma familia em formação (pp. 15-50). Porto Alegre: Artes Médicas.

Burchinal, M. R., Follmer, A., \& Bryant, D. M. (1996). The relations of materna social support and family structure with maternal responsiveness and child outcomes among African American families. Developmental Psychology, 32(6), 1073-1083

Chase-Lansdale, P. L., Brooks-Gunn, J., \& Zamsky, E. S. (1994). Young AfricanAmerican multigeracional families in poverty: quality of mothering and 
grandmothering. Child Development, 65, 373-393.

Dessen, M., \& Braz, M. (2000). Rede social de apoio durante transições familiares decorrentes do nascimento de filhos. Psicologia: Teoria e Pesquisa, 16 , 221-231.

De Wolff, M. S., \& Ijzendoorn, M. H. (1997). Sensitivity and attachment: a metaanalysis on parental antecedents of infant attachment. Child Development, 68(4), 571-591.

Feiring, C., Fox, N. A., Jaskir, J., \& Lewis, M. (1987). The relation between social support, infant risk status and mother-infant interaction. Developmental Psychology, 23(3), 400-405.

Fletcher, R. H., Fletcher, S. W., \& Wagner, E. H. (1996). Freqüência (B. B. Duncan \& M. I. Schmidt, Trad.). In R. H. Fletcher, S. W. Fletcher \& E. H. Wagner (Org.), Epidemiologia clínica: elementos essenciais (3 ${ }^{\mathrm{a}}$ ed., pp. 84-102). Porto Alegre: Artes Médicas.

Floresheim, P., Tolan, P., \& Gorman-Smith, D. (1998). Family relationships, parenting practices, the availability of male family members, and the behavior of inner-city boys in single-mother and two-parent families. Child Development, 69(5), 1437-1447.

Grupo de Interação Social, Desenvolvimento e Psicopatologia - GIDEP/UFRGS/ CNPq (1998a). Ficha de Contato Inicial. Instrumento não-publicado. Instituto de Psicologia. Universidade Federal do Rio Grande do Sul.

Grupo de Interação Social, Desenvolvimento e Psicopatologia - GIDEP/UFRGS/ CNPq (1998b). Termo de Consentimento Livre e Esclarecido. Instrumento não-publicado. Instituto de Psicologia. Universidade Federal do Rio Grande do Sul.

Grupo de Interação Social, Desenvolvimento e Psicopatologia - GIDEP/ UFRGS/CNPq (1998c). Entrevista de Dados Demográficos. Instrumento não-publicado. Instituto de Psicologia. Universidade Federal do Rio Grande do Sul.

Grupo de Interação Social, Desenvolvimento e Psicopatologia - GIDEP/UFRGS/ CNPq (1999). Observação da Interação Familiar - 3o mês. Instrumento não-publicado. Instituto de Psicologia. Universidade Federal do Rio Grande do Sul.

Heck, K. E., \& Parker, J. D. (2002). Family structure, socioeconomic status, and access to health care for children. Health Services Research, 37(1), 173-186.

Hertz, R., \& Ferguson, F. I. (1998). Only one pair of hands: ways that single mothers stretch work and family resources. Community Work and Family, 1(1), 13-37.

Hollingshead, A. B. (1975). Four factor index of social status. Manuscrito nãopublicado, Departmento de Sociologia, Yale University, New Haven.

Isabella, R. A., Belsky, J., \& Von Eye, A. (1989). Origins of infant-mother attachment: an examination of interactional synchrony during the infant's first year. Developmental Psychology, 25(1), 12-21.
Landry, S. H., Smith, K. E., Swank, P. R., Assel, M. A., \& Vellet, S. (2001). Does early responsive parenting have a special importance for children's development or is consistency across early childhood necessary? Development Psychology, $37(3), 387-403$

Nachmias, C. F., \& Nachmias, D. (1996). Research designs: cross-sectional and quasi-experimental designs. In C. F. Nachmias \& D. Nachmias (Orgs.), Research methods in the social sciences (pp. 125-151). Londres: Arnold.

Parke, R. D. (1996). Fathers' involvement: infancy and beyond. In R. D. Parke(Org.), Fatherhood: myths and realities (pp. 44-72). Cambridge, Massachusetts: Harvard University Press.

Piccinini, C. A., Tudge, J. R., Lopes, R. C., \& Sperb, T. (1998). Projeto longitudinal de Porto Alegre: da gravidez à escola. Manuscrito não-publicado, Curso de Pós-Graduação em Psicologia do Desenvolvimento, Universidade Federal do Rio Grande do Sul, Porto Alegre.

Stern, D. N. (1997). A constelação da maternidade (M. A. V. Veronese, Trad.). In D. N. Stern (Org.), A constelação da maternidade: o panorama da psicoterapia pais/bebê (pp. 161-178). Porto Alegre: Artes Médicas.

Tolson, T. F. J., \& Wilson, M. N. (1990). The impact of two and three-generation black family structure on perceived family climate. Child Development, 61, 416-428.

van den Boom, D. C. (1994). The influence of temperament and mothering on attachment and exploration: an experimental manipulation of sensitive responsiveness among lower-class mothers with irritable infants. Child Development, 65, 1449-1469.

Wagner, A. (2002). Possibilidades e potencialidades da família: a construção de novos arranjos a partir do recasamento. In A. Wagner (Org.), Família em cena: tramas, dramas e transformações (pp. 23-38). Petrópolis: Vozes.

Wakschlag, L. S., \& Hans, S. L. (1999). Relation of maternal responsiveness during infancy to the development of behavior problems in high-risk youths. Developmental Psychology, 35(2), 569-579.

Wendland-Carro, J., Piccinini, C. A., \& Millar, W. S. (1999). The role of early intervention on enhancing the quality of mother-infant interaction. Child Development, 70(3), 713-721

Wilson, M. N. (1986). The black extended family: an analytical consideration. Developmental Psychology, 22, 246-258.

Winnicott, D. W. (1971). E o pai? (A. Cabral, Trad.). In D. W. Winnicott (Org.), A criança e o seu mundo (2 $2^{\mathrm{a}}$ ed., pp. 127-133). Rio de Janeiro: Zahar. (Original publicado em 1965)

Ziv, Y., \& Cassidy, J. (2002). Maternal responsiveness and infant irritability: the contribution of Crockenberg and Smith's “Antecedents of mother-infant interaction and infant irritability in the first 3 months of life". Infant Behavior and Development, 25, 16-20. 
${ }^{1} \mathrm{O}$ termo mãe casada será utilizado neste estudo para caracterizar as situações em que o casal mora junto, tendo ou não oficializado a união.

Cesar Augusto Piccinini, doutor em Psicologia pela Universidade de Londres (Inglaterra), é pesquisador do CNPq e professor associado no Instituto de Psicologia, Universidade Federal do Rio Grande do Sul (UFRGS). Endereço para correspondência: Rua Ramiro Barcelos 2600/111; Porto Alegre, RS; CEP 90035-003. Tel./ Fax: (51) 3308-5246. E-Mail: piccinini@portoweb.com.br

Angela Helena Marin, mestre e doutoranda do Programa de Pós-Graduação em Psicologia da UFRGS, é professora no curso de Psicologia da Universidade Luterana do Brasil. E-mail: ahmarin@hotmail.com Patrícia Alvarenga, doutora em Psicologia pela UFRGS, é professora adjunta no Departamento de Psicologia, Universidade Federal da Bahia. E-Mail: palvarenga66@gmail.com

Rita de Cássia Sobreira Lopes, doutora em Psicologia pela Universidade de Londres, é professora na Universidade Federal do Rio Grande do Sul. E-Mail: sobreiralopes@portoweb.com.br Jonathan Richard Henry Tudge é professor de Desenvolvimento Humano e Estudo da Família, Universidade da Carolina da Norte (Greensboro, EUA). E-Mail: jrtudge@uncg.edu 